\title{
Back analysis of a natural jointed rock slope based on the photogrammetry method
}

\author{
Dong-Hyun Kim Griffith School of Engineering, Griffith University, Australia \\ Ivan Gratchev Griffith School of Engineering, Griffith University, Australia \\ Arumugam Balasubramaniam Griffith School of Engineering, Griffith University, Australia
}

\begin{abstract}
In 2013, a potentially unstable jointed rock slope above a road in the Gold Coast area, Australia, partially failed after a rainfall event. In this study, the rock failure was back analysed to evaluate the presence of key blocks through block analysis based on photogrammetry surveys. Friction angles of the joint sets at the point of failure were also investigated by means of a parametric study using a 3D distinct element method (DEM).

The photogrammetry method was employed to obtain measurements of the orientation of the joint sets of the slope and the shape and size of rock blocks at the inaccessible slope. The joint roughness coefficient (JRC) obtained from the 3D photogrammetry model was utilised to estimate friction angles and the strength of the joint set.

Safety factors of the rock mass were computed by both analytical and numerical approaches. Parametric analyses, using a DEM model, assessed the critical friction angle of the joint sets and also demonstrated the failure mechanism of the blocks. The result of this study indicates that the obtained safety factors are in agreement with the block analysis and the results from the numerical analysis performed by the distinct element code "3DEC".
\end{abstract}

Keywords Block theory $\cdot$ Photogrammetry $\cdot \mathrm{JRC} \cdot$ Distinct element modelling 


\section{Introduction}

The stability of jointed rock masses is strongly affected by the orientations of joints sets. Based on the discontinuity data, feasible failure mechanisms can be initially assessed by kinematic analyses. Further, in hard rock slopes, if the rock blocks are assumed to be rigid and the joint sets are assumed to be fully persistent through the volume of interest, block theory can investigate the finiteness and removability of individual blocks surrounded by multiple joint systems.

Block theory is an analytical method developed by Goodman and Shi (1985) to assess the stability of rock mass with discontinuities. The method provides a three-dimensional graphical presentation of the problem and assists in identifying removable blocks and also finding the applicable failure modes. This simple approach has provided research with a comprehensive stability evaluation of jointed rock slopes with a clearly defined geometry of blocks (Goodman and Shi, 1985; Mauldon and Goodman, 1996; Hatzor and Goodman., 1997; Tonon, 1998; Huang et al., 2003; Hatzor and Feintuch, 2005; Kulatilake et al., 2011).

The application of block theory should be based on accurate measurements of the discontinuity characteristics, however it has limited application as it is difficult to obtain during field investigations of large slopes. Thus, the geo-referenced three-dimensional models obtained from remote sensing techniques such as laser scanning and terrestrial digital photogrammetry started to be employed to provide the geo-structural data for the key block analyses (Pötsch et al., 2006; Ferrero et al., 2011a,b).

The terrestrial photogrammetry method is an alternative to traditional survey methods and greatly reduces the time required at potentially hazardous rock slopes. Using a digital single lens reflex (DSLR) camera and commercially available software packages, the applicability of photogrammetry to measure the orientation of discontinuities in large natural rock slopes and open pits has been investigated by many researchers (Poropat, 2009; Haneberg, 2008; Sturzenegger and Stead, 2009; Firpo et al., 2011; Brideau et al., 2011; Brideau and Stead, 2012). Moreover, 3D photogrammetry surface models can assist engineers with obtaining the joint surface roughness characteristics, including the joint roughness coefficient (JRC) (Haneberg, 2007; Poropat, 2009; Guo et al., 2011; Kim et al., 2013a,b), which helps to constrain values of joint friction.

This study seeks to apply the block theory in combination with photogrammetry to backcalculate the rock block failure in a potentially unstable slope in the Tamborine Mountain area, Gold Coast, Australia. This slope has long experienced stability issues affecting the 
serviceability of the adjacent road. Thus, the slope has been visited and observed occasionally by the authors. After the failure, photogrammetry was employed to provide discontinuity characteristics to key block analysis, so as to identify key blocks at failure conditions. The behaviour of rock failures was then produced by the 3D distinct element code "3DEC" simulations. The friction angles along joint surfaces were back-calculated using parametric simulations, comparing them with the safety factor for removable blocks.

\section{Study area and photogrammetry survey}

\subsection{Geology}

The studied slope (Fig. 1) is located along Henri Robert Drive in the Tamborine Mountain area, Gold Coast, Australia. The height of the slope is up to 25 meters and the geological composition is mainly greywacke of the Neranleigh-Fernvale Beds (Willmott, 2010, Gratchev et al., 2013). This slope has experienced stability issues in the past few years especially during heavy rainfalls, and for this reason, its condition has been regularly monitored due to the importance of the adjacent traffic route.

A block failure occurred at the study area in January 2013 during heavy rainfall. The rock mass in the failed area posed a threat to the serviceability of the road, and its stability became a concern for the local community. Figure 1 compares the failed rock mass with the picture taken during the 2012 pre-failure site investigation.

Field observations indicated that the rock in each section was relatively hard and slightly weathered; with most of the joints found to be either planar or undulating without cohesive infill. The rock mass generally consisted of polygonal blocks with the average block volume being in the range of $0.4 \sim 1.8 \mathrm{~m}^{3}$. Several samples were collected for point load tests to estimate the strength of the rocks. From the obtained data, the average unconfined compressive strength (UCS) of $59 \mathrm{MPa}$ was calculated using the empirical correlations between UCS and the point load index proposed by Look and Griffiths (2001) for the rocks in the Gold Coast area.

\subsection{Determination of slope characteristics using photogrammetric model}

Photogrammetry was employed to produce 3D models of the slope and determine the characteristics of blocks and discontinuities. A Nikon D7000 DSLR digital camera with a Nikon Nikkor $24 \mathrm{~mm}$ lens was utilized to capture high-quality images of the slope at two 
camera positions. The computer code "Sirovision" (CAE, 2013) was used to analyze the images and create 3D models of the slope. Sirovision requires the approximate target distance (i.e., the distance between the camera locations and the rock slope) or the baseline length (i.e., the distance between the two camera positions). To successfully create 3D models, Sirovision recommends a length of $1 / 6$ to $1 / 8$ of the target distance as a baseline distance. The camera height above the ground was also determined by a measuring tape. Because the slope was inaccessible due to the safety barrier along the road, the measurements for photogrammetry were performed by measuring the distances and heights of specific target points on the slope using a laser range finder (Nikon Forest Pro). The accuracy of range finders, as stated by the manufacturers, is reported as measurement errors ranging from 0.1 to 3\% (Wing et al., 2004). In this study, the accuracy of the measurement was evaluated by comparing the measurement values of the range finder to the measured distance (from a column of the barrier to the range finder) by a measuring tape. The result shows that the measurement using the laser range finder produced around $1.6 \%$ of measurement error as presented in Table 1 . The slope height was calculated as schematically shown in Figure 2.

Georeferencing was performed by measuring the bearing (azimuth) of each camera position to the center of the slope (using a geological compass) and determining the coordinates of the camera position (using a GPS device), following the procedure described by CSIRO (2005).

Figure 3(a) shows an image of the georeferenced 3D model which is taken in the direction of the photograph $\left(\mathrm{N} 82^{\circ} \mathrm{W}\right) .35$ joint data were obtained from the $3 \mathrm{D}$ model and plotted in a stereonet. The computer code “Dips (Rocscience, 2010)" was then used for the identification of the main joint sets based on the data distribution. Dip and dip directions of the main joint sets are summarized in Table 2. Potential failure modes were identified based on the direction of the slope cut as presented in Figure 3(b). According to the results from kinematic analysis, wedge slides on the intersection line of $\mathrm{J} 1$ and $\mathrm{J} 2$, and planar sliding modes along the joints J3 and J4 were feasible.

\subsection{Friction angles of joints obtained from 3D photogrammetry model}

JRC is an important parameter that contributes to the overall friction of joints. JRCs of the major joint sets were obtained from the 3D photogrammetry model. Sirovision computes the JRC values using the functions suggested by Maerz et al. (1990) and Tse and Cruden (1979). Maerz et al. (1990) proposed to estimate JRC using a regression equation that describes the 
relationship between JRC values and the roughness profile index $\left(R_{p}\right) . R_{p}$ is defined as the ratio of the true length of a fracture surface trace to its projected length in the fracture plane.

$$
\mathrm{JRC}=411\left(\mathrm{R}_{\mathrm{p}}-1\right)
$$

where, $R_{p}$ is the roughness profile index obtained from photo analysis. Tse and Cruden (1979) suggested a statistical approach to Barton and Choubey's standard joint surface profiles (Barton and Choubey, 1977).

$$
\begin{aligned}
& \mathrm{JRC}=32.2+32.47 \log \mathrm{Z}_{2} \\
& \mathrm{JRC}=37.28+16.58 \log \mathrm{SF}
\end{aligned}
$$

where, $Z_{2}$ is the root mean square while $S F$ is the mean square of the first derivative of the profile. Using the above equations, JRC values at ten different locations on each joint set in the failure area were obtained by Sirovision. It was found that the range of JRC obtained from J4 showed considerably lower values than other joints as shown in Table 2. The lower values may be attributed to limitations of photogrammetry survey according to surveying conditions.

Firstly, the resolution of image was relatively low due to the far distance from the slope (See Fig. 2 and Table 1) which created an image with a large pixel size (2.9mm/pixel). Considering the typical size of profile gauge (1mm interval), smaller pixel size of images (less than $1.0 \mathrm{~mm} / \mathrm{pixel}$ ) is preferable to produce accurate value of roughness parameters, such as $Z_{2}$ and SF. Haneberg (2007) stressed the importance of image density to estimate JRC values from 3D models.

Secondly, the values can be affected by a potential orientation bias which means an occlusion when the vertical line-of-sight of the camera is close to parallel to an upward discontinuity (Sturzenegger and Stead, 2009). The inclined roughness profiles may calculate underestimated values of JRC in photogrammetry methods as studied by Hong et al., (2006). Indeed, the vertical line-of-sight of the camera made an acute angle (around $22^{\circ}$ ) with the dip angle of $\mathrm{J} 4$ as shown in Figure 2. However, as planar sliding along the joint J4 was considered as the primary failure mechanism, the range of JRC for J4 (0.3 7.3) was selected to investigate the friction angles of the joint sets (Table 3).

Using the range of JRC values, friction angle of the joints was calculated using the Barton's empirical equation (Eq. 4, Barton et al., 1985) for parametric analyses which will be mentioned later on. The range of residual friction angle $\left(\phi_{\mathrm{r}}\right)$ was assumed from the test results performed by Barton et al., (1973). Results from point load tests were utilized to estimate the 
joint wall compressive strength (JCS). Using Eq.(4), the friction angle of joints considering JRC values was estimated to be from $25^{\circ}$ to $35^{\circ}$ as shown Table 4 .

$$
\phi=\phi_{\mathrm{r}}+\mathrm{JRC}_{\mathrm{n}} \log _{10}\left(\frac{\mathrm{JCS} \mathrm{S}_{\mathrm{n}}}{\sigma_{\mathrm{n}}}\right)
$$

where, $\phi_{\mathrm{r}}=$ residual friction angle of joint; JCS = joint wall compressive strength; $\sigma_{\mathrm{n}}=$ normal stress acting on the joint plane was calculated using the average height of the blocks.

\section{Analyses of failed blocks}

\subsection{Key block analysis}

Sixteen blocks were analyzed for the failure area the results of which are summarized in Table 5. Four major joint sets (J1-J4) together with the slope surface (the dashed line in Fig. 4a) produced three joint pyramids (JP) coded 0001, 1000 and 1001 which were entirely located inside the slope circle. These blocks were considered to be removable following the block theory concept.

\subsection{Safety factors (FS) for removable blocks}

To back-calculate the safety of the removable blocks, a safety factor analysis, which defines the relationship between the resultant force and the effective strength in the direction of sliding, was carried out. This analysis was performed for the dominant plane sliding along the joint J4. Figure 4b graphically represents the shape of removable blocks obtained from the results of block theory analysis. The shapes of vulnerable blocks were also identified based on the 3D models of the failed slope area. Single face sliding (planar mode) along the intersection of $\mathrm{J} 4$ and $\mathrm{J} 3$ was identified for the failure area and the plane sliding along J4 could be the dominant failure mode for the failure area.

Using the equilibrium equation (Eq. 5) (Goodman and Shi, 1995), the net of sliding force (F) was computed. The calculation was performed with a different range of friction angles from $25^{\circ}$ to $55^{\circ}$ according to the results of the JRC measurements (Table 4). A positive $\mathrm{F}$ corresponds to a key block (type I) while a negative F defines the removable block (type II). Table 6 summarizes the results of this analysis using different friction angles. The net of sliding forces indicates negative values when the friction angle is more than $35^{\circ}$. Thus, when the friction angle becomes $35^{\circ}$, JP 0001 changes its block type from key block (type I) to potential key block (type II) as shown in Table 6.

For single face sliding (planar mode): 


$$
\mathrm{F}=\mathrm{W} \sin \alpha_{\mathrm{i}}-\mathrm{W} \cos \alpha_{\mathrm{i}} \tan \phi_{\mathrm{i}}
$$

where, $\mathrm{W}=$ the weight of a block; $\alpha_{\mathrm{i}}=$ dip angles of plane $\mathrm{i} ; \phi_{\mathrm{i}}=$ friction angles of plane The stability of key blocks was assessed using the ratio of the resisting and driving forces. In case of a single plane sliding, the safety factor of key blocks was calculated as follows (Qingyan and Helin, 2011):

$$
F_{S}=\frac{W \cos \psi_{p} \tan \phi+c A}{W \sin \psi_{p}}
$$

where, $\Psi_{\mathrm{p}}=$ the dip of the sliding plane; $\mathrm{c}=$ cohesive strength of joint; $\mathrm{A}=$ the area of the joint; $\mathrm{W}=$ the weight of the sliding block; $\phi=$ the friction angle of joint. Assuming the sliding plane has no cohesive component, Eq. 6 can be modified to include the surface roughness of joints using the Barton's joint shear strength equation (1977).

$$
F_{S}=\frac{\sigma \tan \left(\phi+J R C \log _{10}\left(\frac{J C S}{\sigma}\right)\right) A}{W \sin \psi_{p}}
$$

where, JCS $=$ the compressive strength of joints; $\sigma=$ normal stress acting on the sliding surface. The effect of water pressure on the safety of the key blocks was considered by investigating the water force acting in the tension crack and also in the bedding plane. The safety factors were calculated using the ratio of the resisting and driving forces (Wyllie and Mah, 2004).

Table 7 summarizes the obtained data in the form of safety factors representing likelihood of the key block sliding along the joint J4 for different values of joint friction. When the slope is saturated, the block is unstable even the friction angle is increased up to $40^{\circ}$. The calculation shows that the key blocks are stable when the friction angle of joint is $35^{\circ}$ in dry condition. However, in saturated conditions, the effective friction angle to keep stability is around $45^{\circ}$. This indicates that this result is consistent with the field observations (the blocks indeed failed during heavy rainfall).

\subsection{Numerical analysis}

In order to investigate the failure mechanism of the rock mass, a 3D numerical analysis was carried out using the commercial code 3DEC ver.5.0 (Itasca Consulting Group Inc., 2013) which can simulate large displacement and rotation of individual blocks surrounded by discontinuities. The geometry of the numerical model was created using coordinates obtained from the photogrammetry 3D model and the scale of the failure area was constrained by the 
pre-failure photographs in 2012 and the debris at the base of the slope. 3D models in the upper part of the failure range could not sufficiently have been created because of the image noise caused by surrounding leaves and trees. Due to the limited geometry information from the pre-failure photographs and the insufficient data of the photogrammetric 3D model, the numerical model was created with simplified block shapes and restricted to the failure range. The dominant 4 discontinuity sets were generated in the rock mass with an assumption that the joints obtained from the 3D photogrammetry model are fully persistent through the investigated rock mass. The discontinuity spacing for the failed area was also modeled according to the data measured from the 3D model. The origin of the joint sets in the numerical model was determined by trial and error comparing the locations and directions of the joint sets with the 3D model. Figure 5 presents the numerical model of the failed slope. The analyses were performed on the assumption that there is no movement derived from the surrounding blocks. Thus, the model has fixed blocks which represent the existing rock structure on the slope, as well as kinematically free blocks which could develop sliding failure.

A series of simulations investigated the safety of the jointed rock mass when the friction angles along the joints were reduced from $55^{\circ}$ to $25^{\circ}$. In the numerical models, joint stiffness properties were estimated using the equations suggested by Barton and Choubey (1977). Joint shear stiffness $\mathrm{K}_{\mathrm{s}}$ is calculated as follows:

$$
K_{s}=\frac{100}{L_{x}} \sigma_{n} \tan \left[J R C \log _{10}\left(\frac{J C S}{\sigma_{n}}\right)+\phi_{r}\right]
$$

where, $K_{s}=$ joint shear stiffness $\left(\mathrm{MN} / \mathrm{m}^{2} / \mathrm{m}\right) ; \quad \mathrm{L}_{\mathrm{x}}=$ joint length $(\mathrm{m}) ; \mathrm{JCS}=$ joint wall compressive strength $\left(\mathrm{MN} / \mathrm{m}^{2}\right) ; \sigma_{\mathrm{n}}=$ normal stress $\left(\mathrm{MN} / \mathrm{m}^{2}\right)$ acting on the joint plane was calculated using the average height of the blocks. Table 8 summarizes the properties of rock joints adopted for the numerical analyses.

The results indicated that the overall stability of the jointed rock mass was controlled by the friction angle of joints (See Table 7). The safety factor (SF) calculated by 3DEC decreased with a reduction in joint friction angles. Also, the values of SF are in agreement with the data obtained through the key block analysis, which indicate the range of values between dry conditions and saturated conditions. In the simulation, the critical friction angle ( $\left.35^{\circ}\right)$ is close to the dip angle of the joint $\mathrm{J} 4\left(32^{\circ}\right)$.

At the condition of failure, the mechanism appeared to be planar sliding. Along the joint J4, sliding of blocks with rotation started from the upper portion of the slope. This result can be 
due to the fixed block located in the lowest portion (block no.9 in Fig. 6a) which remained on the slope after the failure. In addition, this was attributed to the dip direction of the flat joint plane oriented northeasterly $32^{\circ}$.

The results are consistent with the calculation obtained by block theory. Note that the maximum displacement vectors are associated with the key blocks as shown in Figure 6a 6d. It was observed that the displacement started from the blocks shaped JP 1001 and JP 0001(block no. 1,3,4,6 in Fig. 6). Then, the sliding of 2, 5 and 7 blocks (tapered) occurred due to the space created by the first sliding blocks.

\section{Conclusion}

The key block theory combined with photogrammetry was applied to back calculate the critical friction angle of the joints on a locally failed natural rock slope. A jointed rock mass that had experienced slope failure was characterized using photogrammetric surveys and photographs taken from a pre-failure investigation. Based on the 3D model, key blocks for the rock mass were identified and the safety factors of the blocks were assessed by analytical methods.

The study found that the safety factor of key blocks was greatly reduced when pore water pressure was considered and the critical friction angle to satisfy the stability in the saturated condition increased from $35^{\circ}$ to $45^{\circ}$. This result provides a feasible mechanism for the block failure which occurred at the site in January 2013 during heavy rainfall. In addition, JRC values obtained from the photogrammetry 3D model suggested a range of friction angles of joints on the surveyed slope. However, the accuracy of the JRC values can be affected by image density and the angles between the vertical line-of-sight of the camera and the joint dip angles. Also, the safety factors obtained from numerical studies using the 3DEC code were consistent with the results from the key block theory analysis. The simulation results demonstrated that the failure was initiated by the movement of key blocks with planar and rotational modes.

\section{Acknowledgement}

The authors would like to express their appreciation to Mr. George Poropat from CSIRO for the valuable help with this research. 


\section{Reference}

Barton N (1973) Review of a new shear-strength criterion for rock joints. Engineering Geology 7:287-332

Barton N, Bandis S, Bakhtar K (1985) Strength, deformation and conductivity coupling of rock joints. Int J Rock Mech Min Sci \& Geomech Abstr 22(3):121-140

Barton N, Choubey V (1977) The shear strength of rock joints in theory and practice. Rock Mechanics 10:1-54

Brideau M-A, Sturzenegger M, Stead D, Jaboyedoff M, Lawrence M, Roberts N, Ward B, Millard T, Clague J (2011) Stability analysis of the 2007 Chehalis lake landslide based on long-range terrestrial photogrammetry and airbone LiDAR data. Landslides 9:75-91

Brideau M-A, Stead D (2012) Evaluating kinematic controls on planar translational slope failure mechanisms using three-dimensional distinct element modelling. Geotech Geol Eng 30:991-1011

CSIRO (2005) Field procedures for photogrammetric pit mapping. CSIRO Exploration \& Mining

Wyllie DC, Mah CW (2004) Rock slope engineering. $4^{\text {th }}$ edn, Taylor \& Francis

Ferrero AM, Migliazza M, Roncella R, Rabbi E (2011a) Rock slopes risk assessment based on advanced geostructural survey techniques. Landslides 8:221-231

Ferrero AM, Migliazza M, Roncella R, Segalini A (2011b) Rock cliffs hazard analysis based on remote geostructural surveys: The Campione del Garda case study (Lake Garda, Northern Italy). Geomorphology 125:457-471

Firpo G, Salvini R, Francioni M, Ranjith PG (2011) Use of digital terrestrial photogrammetry in rocky slope stability analysis by distinct elements numerical methods. Int J Rock Mech Min Sci 48:1045-1054

Goodman RE, Shi G-H (1985) Block theory and its application to rock engineering, PrenticeHall Inc., New Jersey

Gratchev I, Shokouhi A, Kim DH, Stead D, Wolter A (2013) Assessment of rock slope stability using remote sensing technique in the Gold Coast area, Australia. Proceedings of Advances in geotechnical infrastructure, Singapore, pp 729-734

Guo H, Karekal S, Poropat G, Soole P, Lambert C (2011) Pit wall strength estimation with 3D imaging. CSIRO, ACARP 
Haneberg WC (2007) Directional roughness profiles from three-dimensional photogrammetric or laser scanner point clouds. $1^{\text {st }}$ Canada-U.S. Rock Mechanics symposium, Vancouver, pp 101-106

Haneberg WC (2008) Using close range terrestrial digital photogrammetry for 3-D rock slope modelling and discontinuity mapping in the United States. Bull Eng Geol Environ 67:457469

Hatzor YH, Goodman RE (1997) Three-dimensional back-analysis of saturated rock slopes in discontinuous rock-a case study. Geotechnique 47(4):817-839

Hatzor YH, Feintuch A (2005) The joint intersection probability. Int Jour Rock Mech Min Sci 42:531-541

Hong ES, Lee IM, Lee JS (2006) Measurement of rock joint roughness by 3D scanner. Geotechnical Testing Journal 29(6), Paper ID GTJ100169

Huang TK, Chen JC, Chang CC (2003) Stability analysis of rock slopes using block theory, Journal of the Chinese institute of Engineers 26(3):353-359

Itasca Consulting Group Inc. (2013) 3DEC Version 5.0 User's Guide, Minneapolis, Minnesota USA

Kim DH, Gratchev I, Balasubramaniam AS (2013a) Determination of joint roughness coefficient (JRC) for slope stability analysis: a case study from the Gold Coast area, Australia. Landslides 10:657-664

Kim DH, Gratchev I, Poropot GV (2013b) The determination of joint roughness coefficient using three-dimensional models for slope stability analysis. Proceedings of Slope stability 2013, Brisbane, pp 281-289

Kulatilake PHSW, Wang L, Tang H, Liang Y (2011) Evaluation of rock slope stability for Yujian River dam site by kinematic and block theory analyses. Computers and Geotechnics 38:846-860

Lato M, Vöge M (2012) Automated mapping of rock discontinuities in 3D lidar and photogrammetry models. Int J Rock Mech Min Sci 54:150-158

Look BG, Griffiths SG (2001) An engineering assessment of the strength and deformation properties of Brisbane rocks. Australian Geomechanics 36(3):17-30

Maerz NH, Franklin JA, Bennett CP (1990) Joint roughness measurement using shadow profilometry. Int J Rock Mech Min Sci 27:329-343

Mauldon M, Goodman RE (1996) Vector analysis of keyblock rotations. J Geotech Engineering 122 (12):976-987 
Poropat GV (2009) Measurement of surface roughness of rock discontinuities. Proceedings of $3^{\text {rd }}$ CANUS Rock Mechanics Symposium, Toronto, Canada, paper 3976

Pötsch M, Schubert W (2006) Kinematic analysis of rock blocks supported by 3D imaging. Proceedings of the $41^{\text {st }}$ U.S. Symposium on Rock Mechanics (USRMS), paper 1079

Qingyan T, Helin F (2011) Block theory rock joint length modifying and slope stability analysis, Geotechnical Special Publication No.216, ASCE:56-64

Sturzenegger M, Stead D (2009) Close-range terrestrial digital photogrammetry and terrestrial laser scanning for discontinuity characterization on rock cuts. Engineering Geology 106:163-182

Tse R, Cruden DM (1979) Estimating joint roughness coefficients. Int J Rock Mech Min Sci 16:303-307

Tonon F (1998) Generalization of Mauldon’s and Goodman's vector analysis of keyblock rotations. J Geotech Geoenviron Eng 124(10):913-922

Willmott WF (2010) Rocks and landscape of the Gold Coast hinterland. Geological society of Australia, Queensland division

Wing MG, Solmie D, Kellogg, L (2004) Comparing digital range finders for forestry applications. Journal of Forestry 102(4):16-20 


\section{List of Figures}

Fig. 1 Overview of the study area (a), before failure (b) and enlarged image of the failure area (c)

Fig. 2 Layout and parameters of the photogrammetric survey

Fig. 3 3D surface model and main joint sets identified using by "Sirovision" (a) and stereonet projection (b) of the main joint sets

Fig. 4 Identification of removable blocks using stereographic projection (a) and the removable blocks (b)

Fig. 5 Dimensions and geometry of the 3DEC model

Fig. 6 3DEC simulation results at (a) 10,000, (b) 15,000, (c) 20,000, (d) 25,000 cycles 